\title{
Design Optimization of Reinforced Concrete Frames
}

\author{
Abobakr A. A. Aga1, Fathelrahman M. Adam²,3 \\ ${ }^{1}$ Saudi Automotive Services Company, Jedah, KSA \\ ${ }^{2}$ Department of Civil Engineering, Jazan University, Jazan, KSA \\ ${ }^{3}$ Nile Valley University, Khartoum, Sudan \\ Email: al gaim@hotmail.com, fat470@yahoo.com
}

Received 12 February 2015; accepted 1 March 2015; published 3 March 2015

Copyright (C) 2015 by authors and Scientific Research Publishing Inc.

This work is licensed under the Creative Commons Attribution International License (CC BY). http://creativecommons.org/licenses/by/4.0/

(c) (i) Open Access

\begin{abstract}
In this paper, a design optimization for the reinforced concrete plane frame structure has been done in order to minimize the cost of the concrete and steel for beams and columns by adopting the Artificial Neural Network (ANN) computational model trough the NeuroShell-2 software program. The design procedure conforms to the ACI-318-08 Code. The variables used for design optimization are the width, depth and the area of reinforced steel, including longitudinal reinforcement and shear reinforcement. A three-bay two-story $\mathrm{RC}$ frame is modeled with selecting different span length and different load cases. Acceptable design results are obtained from more than $\mathbf{5 0}$ examples which are subjected to all the constraints of the ACI Code, using different cross-section sizes and these results are used to train the NeuroShell-2 program. The results obtained demonstrate the efficiency of the ANN procedure for the multi story RC frame design.
\end{abstract}

\section{Keywords}

Optimization Design, RC Beam Design, RC Column Design, Artificial Neural Network

\section{Introduction}

Following the requirements of any code of practice in order to design beams and columns and with obtaining many acceptable cross sections, most engineers are in hesitation with selecting suitable cross sections that lead to minimize cost without further calculations. This paper adopts design optimization model to contribute to helping engineers to select simply a suitable dimensions for beams and columns in order to minimize the cost of concrete, steel, and formwork.

The optimum solution concerning structural engineer began with Michell [1] and was followed by Schmidt 
[2]. Heyman identified the absolute minimum weight of continuous beam [3]. During the past two decades, following recent developments in the field of design optimization of RC structures, a number of researchers have employed mathematical and evolutionary search techniques to optimum design subject to combination of gravity and lateral loadings. Krishnamoorthy and Munro [4] used linear programming techniques to optimize reinforced concrete frames [5]. Moharrami and Grierson [6] presented an automated computer-based method to design optimization of RC building frameworks subject to constraints on strength and stiffness. In more recent studies, Lee and Ahn [7], and Camp et al. [8] implemented Genetic Algorithms (GA) that searched for discrete-valued solutions of beam and column members in RC frames. Andres and Panos [9] worked on optimal design of reinforced concrete (RC) structures. Sara et al. modeled an Artificial Neural Networks (ANN) to optimize cost of simply supported beams [10].

Artificial Neural Networks (ANN) are generally presented as systems of interconnected "neurons" which can compute values from inputs. It began to use at first in 1940s by Warren McCulloch and Walter Pitts (1943) by creating computational mode based on mathematics algorithms and was followed by Donald Hebb (1948) which created a hypothesis of learning based on the mechanism of neural plasticity. Farley and Wesley A. Clark (1954) first used computational machines [11]. The Artificial Neural Network is built with a systematic step-by-step procedure to optimize a performance criterion or to follow some implicit internal constraint, which is commonly referred to as the learning rule [10]. ANN have been used in the fields of concrete structures for nearly 25 years by many researchers: Tang et al. (2003), Oreta (2004), Fonseca et al. (2003), D. Maity and A. Saha (2004). These researchers basically set the structural parameters such as the material property, the boundary condition and the size of a structure as the input of the ANN model to predict the ability for the structure to resist the load [12]. In most of these works, the neural networks have been trained by using back propagation algorithm. In this approach, the connection weights of neural networks are initially set to some random values. These values are then modified automatically according to the learning algorithm during the process of learning.

\section{Design Optimization of RC Frames}

Formulation of the optimal design problem requires identification of design variables for the structural system, objective function that needs to be minimized, and design constrains that must be imposed on the system. Once the design problem has been formulated, it is transcribed into the following standard constrained optimization model:

\subsection{Design Variables}

Using one column size for each story or for a number of stories and varying the amount of reinforcement will simplify construction form. For a line of continuous beams, keeping the beam size constant, even when loads and spans differ, and varying the amount of reinforcement from span to span will also simplify the construction of forms. In both cases, less labor will be used, fewer supervisors and inspectors will be needed, and costs will be lower. These ideas are employed in this study as the basis of a general strategy for frame economy.

For the present formulation, cross-sectional dimensions and reinforcement areas for columns and beams are taken as design variables. Specifically, for columns there exist three design variables: the width, $b_{c}$, the effective depth, $d_{c}$ and the longitudinal reinforcing steel area, $A_{S t}$ Also, for beams there exist three design variables: the width and the effective depth of the web, $b_{w}$ and $d_{b}$, respectively, and the tensile reinforcing steel area, $A_{s}$. For each story, the design variables pertaining to the concrete sections are linked, meaning that the column width are assigned the same design variable as well as each of the column effective depths, beam widths, and beam effective depths. This gives practical designs facilitating the use of repetitive formwork. For each story, there are only two design variables pertaining to the reinforcing steel. These are the longitudinal reinforcing steel area in the most critical column and the tensile reinforcing steel area at the most critical location of bending moment in beams. Each member contains only the minimum amount of area of steel that required satisfying the imposed constraints.

\subsection{Objective Function}

The objective function which must be minimized is the function calculates the total cost of the frame. It is expressed in terms of concrete volume, steel weight, formwork surface area as well as their unit costs. The total 
cost of a reinforced concrete plane frame can be expressed as:

$$
\text { Cost }=C_{\text {columns }}+C_{\text {beams }}
$$

where:

$C_{\text {columns }}=$ cost of columns for the whole frame.

$C_{\text {beams }}=$ cost of beams for the whole frame.

These costs can be calculated according to the following formulations

$$
\begin{gathered}
C_{\text {columns }}=C_{C} n_{C} \sum_{i=1}^{N_{S}}\left(V_{C C}-V_{C S}-V_{t}\right)_{i}+C_{S} n_{C} \gamma_{S} \sum_{i=1}^{N_{S}}\left(V_{C S}+V_{t}\right)_{i}+C_{f} n_{C} \sum_{i=1}^{N_{S}}\left(A_{C f}\right)_{i} \\
C_{\text {beams }}=C_{C} n_{b} \sum_{i=1}^{N_{S}}\left(V_{b C}-V_{b S}-V_{v}\right)_{i}+C_{S} n_{b} \gamma_{S} \sum_{i=1}^{N_{S}}\left(V_{b S}+V_{v}\right)_{i}+C_{f} n_{b} \sum_{i=1}^{N_{S}}\left(A_{b f}\right)_{i}
\end{gathered}
$$

where:

$C_{C}=$ cost of concrete per unit volume.

$C_{S}=$ cost of steel, ties, and stirrups per unit weight.

$C_{f}=$ cost of formwork per unit surface area.

$N_{S}=$ number of stories.

$n_{C}=$ number of columns per story.

$n_{b}=$ number of beam per story.

$\gamma_{S}=$ unit weight of steel.

$V_{C C}=$ volume of concrete in a column, calculated by using Equation (4).

$V_{C S}=$ volume of longitudinal reinforcing steel in a column, calculated by using Equation (5).

$V_{t}=$ volume of lateral ties in a column, calculated by using Equation (6).

$A_{C f}=$ surface area of formwork for a column.

$V_{b C}=$ volume of concrete in a beam, calculated by using Equation (7).

$V_{b S}=$ volume of tensile reinforcing steel in a beam, calculated using Equation (8).

$V_{v}=$ volume of stirrups in a beam, calculated using Equation (9).

$A_{b f}=$ surface area of formwork for a beam.

$$
V_{C C}=A_{g c} L_{u}
$$

where

$A_{g c}=$ gross cross-sectional area of column.

$L_{u}=$ unsupported length (clear height) of column.

$$
V_{c s}=A_{s t} L_{c b a r s}
$$

where

$A_{s t}=$ cross-sectional area of longitudinal steel.
$L_{\text {cbars }}=$ length of column longitudinal reinforcing steel bars.

$$
V_{t}=A_{t} L_{\mathrm{tie}} n_{t}
$$

where

$A_{t}=$ cross-sectional area of bars used for ties.

$L_{\text {tie }}=$ length of one tie.

$$
V_{b c}=A_{g b} L_{b}
$$

where:

$A_{g b}=$ gross cross-sectional area of beam.

$L_{b}=$ length of beam between column center lines.

$$
V_{b s}=A_{s} L_{b b a r s}
$$

$A_{s}=x$-sectional area of longitudinal bars include tension and compression steel.

$L_{\text {bbars }}=$ length of beam longitudinal reinforcing steel bars. 


$$
V_{v}=A_{v} L_{v} n_{s}
$$

where

$A_{v}=$ cross-sectional area of bars used for stirrups.

$L_{v}=$ length of one stirrup.

$n_{s}=$ number of stirrups in one beam.

For more details about calculating volumes of materials can be referred to Reference [13].

\subsection{Design Constraints}

The constraints on the design consist of two types: structural constraints, such as code requirements and serviceability criteria, and size limitation constraints. Structural constraints are in accordance with the ACI 318-08 Code provisions. In the following there are column's constraints and beam's constraints categorize as geometric constraint and constraints deducted according to the requirements of ACI Code for the design of column and beam.

\subsubsection{Column Constraints}

\section{1) Geometric constraint}

For the present formulation, columns may be square or rectangular. In order to ensure that the width of the column $\left(b_{c}\right)$ will not exceed its depth $\left(h_{c}\right)$, the column dimensions are constrained by:

$$
\frac{b_{c}}{h_{c}}-1.0 \leq 0
$$

\section{2) Capacity constraint}

The ACI Code establishes adequate safety margins for columns by applying overload factors to the service loads and strength reduction factors to the nominal ultimate strengths. Therefore, $P_{u} \leq \varphi P_{n}$ is a basic safety criteria, where $P_{u}$ is the factored axial load at a given eccentricity, $P_{n}$ is the nominal axial strength at a given eccentricity , and $\varphi$ is a strength reduction factor, equals 0.7 for tied columns.

For columns with very small or zero calculated eccentricities, the ACI Code recognizes that accidental construction misalignments and other unforeseen factors may produce actual eccentricities in excess of these small design values. Regardless of the magnitude of the calculated eccentricities, the ACI Code limits the maximum design strength to $0.8(\varphi) P_{0}$ for tied columns. Here, $P_{0}$ is the nominal strength of the axially loaded column with zero eccentricity.

This results in:

$$
P_{u} \leq(0.8)(0.7) P_{0}
$$

where

$$
P_{0}=0.85 f_{c}^{\prime}\left(A_{g c}-A_{s t}\right)+A_{s t} f_{y}
$$

By substituting Equation (13) in Equation (12), then Equation (12) can be rewrite in normalized form as:

$$
1.0-\frac{0.476 f_{c}^{\prime}\left\{b_{c} h_{c}-A_{s t}\right\}+0.56 A_{s t} f_{y}}{P_{u}} \leq 0
$$

\section{3) Minimum area of reinforcing steel constraint}

Columns are designed on the basis of the interaction between combined bending and axial load. However, since the axial load has direct influence on the moment capacity of the column, and vice versa, there is no simple way of uncoupling the two effects.

The ACI Code allows the steel ratio to vary from a minimum of 1 percent to a maximum of 8 percent. To establish the required constraint, it is necessary to write the required steel ratio $\rho_{g}$ in terms of the applied factored moment $M_{u}$. This can be done by observing that in the ductile range for typical interaction diagrams the required steel ratio varies linearly with the applied moment. Since most interaction diagrams express the applied moment as a no dimensional quantity, this can be expressed as: 


$$
\rho_{g}=0.02+\frac{0.06 M_{u}}{1.25 A_{g c} h_{c}}
$$

where $h_{c}$ is the column dimension in the direction of bending, But $\rho_{g}$ can be easily expressed in terms of the design variables as:

$$
\rho_{g}=\frac{A_{s t}}{b_{c} h_{c}}
$$

Therefore, the final constraint is given as:

$$
1.0-\frac{A_{s t}}{0.02 b_{c} h_{c}+0.048 \frac{M_{u}}{h_{c}}} \leq 0
$$

Here, $M_{u}$ is the factored bending moment applied on the most critical column in a story and is obtained from the analysis.

\section{4) Maximum reinforcing steel area constraint}

To ensure that the column steel ratio $\rho_{g}$ does not exceed the ACI Code limit $\rho_{g \text { max }}$ of 8 percent, the following constraint is imposed:

$$
\rho_{g} \leq \rho_{g \max }
$$

By expressing two constraints of Equation (17) and Equation (18) in terms of the design variables and put them in the normalized form, the final constraint can be written as:

$$
\frac{A_{s t}}{0.08 b_{c}\left(d_{c}+d^{\prime}\right)}-1.0 \leq 0
$$

\subsubsection{Beam Constraints}

\section{1) Geometric constraints}

Reinforced concrete beams may be wide and shallow requiring compression steel, or relatively narrow and deep with no compression steel. Consideration of maximum material economy often leads to proportions with effective depth $\left(d_{b}\right)$ in the range from about 1.5 to 2.0 times the width $\left(b_{w}\right)$. This results in the following constraints:

$$
1.0-\frac{d_{b}}{1.5 b_{w}} \leq 0
$$

and

$$
\frac{d_{b}}{2.0 b_{w}}-1.0 \leq 0
$$

\section{2) Flexural capacity constraint}

All beams are designed to ensure that the moment produced by factored loads $M_{u}$ does not exceed the available flexural design strength $\varnothing M_{u}$ of the cross section at any point along the length of the beam. Here, $\varnothing$ equals 0.9 , and $M_{n}$ is the nominal moment capacity of the cross section. Mathematically, this can be written as:

$$
M_{u} \leq \varnothing M_{n}
$$

According to the ACI Code, the design strength in flexure of a cross section (without compression reinforcement) may be expressed as:

$$
\varphi M_{n}=\varnothing\left[A_{s} f_{y}\left(d_{b}-\frac{a}{2}\right)\right]
$$

where $a$ is the depth of the equivalent rectangular stress block, and can be computed by 


$$
a=\frac{A_{s} f_{y}}{0.85 f_{c}^{\prime} b_{w}}
$$

Substituting Equation (23) into Equation (23), this orderly substitute into Equation (22) which gives the following constraint:

$$
M_{u} \leq 0.9\left[A_{s} f_{y}\left(d_{b}-\frac{A_{s} f_{y}}{1.7 f_{c}^{\prime} b_{w}}\right)\right]
$$

or, in the normalized form

$$
1.0-\frac{0.9}{M_{u}}\left[A_{s} f_{y}\left(d_{b}-\frac{A_{s} f_{y}}{1.7 f_{c}^{\prime} b_{w}}\right)\right] \leq 0
$$

\section{3) Minimum reinforcing steel area constraint}

According to ACI Code, the ratio of steel is limited to the value of $\rho_{\min }$ by the equation:

$$
\rho_{\min }=\frac{200}{f_{y}}
$$

Thus, the following constraint can be imposed on the beam steel ratio $\rho$ :

$$
\rho \geq \rho_{\text {min }}
$$

Expressing $\rho$ in terms of the design variables and putting in the normalized form, the final constraint can be written as:

$$
1.0-\frac{A_{s} f_{y}}{200 b_{w} d_{b}} \leq 0
$$

\section{4) Maximum reinforcing steel area constraint}

In order to have reasonable assurance that concrete beams fail in a ductile manner under flexure, the ACI Code limits the amount of tension steel to not more than 75 percent of the amount in the balanced strain that is:

$$
\rho=0.75 \rho_{b}
$$

where:

$$
\rho_{b}=0.85 \frac{f_{c}^{\prime}}{f_{y}} \beta_{1}\left[\frac{87000}{87000+f_{y}}\right]
$$

in which:

$$
\beta_{1}=0.85-0.05\left[\frac{f_{c}^{\prime}-4000}{1000}\right] \geq 0.65
$$

Equation (32) used for $f_{c}^{\prime}$ greater than 4000 psi and instead use a value of 0.85 for $\beta_{1}$ for $f_{c}^{\prime}$ less than 4000 psi.

This limitation will provide adequate ductile behavior for most design. One condition where greater ductile behavior is required is in design for redistribution of moments in frames. Since moment redistribution is dependent on adequate ductility in hinge regions, the ACI Code 318-83 Commentary limits the amount of tension steel hinging regions by:

$$
\rho_{\text {max }}=0.5 \rho_{b}
$$

Thus, the following constraint can be imposed:

$$
\rho \leq \rho_{\max }
$$

Expressing $\rho$ in terms of the design variables and putting in the normalized form, the final constraint can be expressed as: 


$$
\frac{A_{s}}{0.5 \rho_{b} b_{w} d_{b}}-1.0 \leq 0
$$

5) Shear strength requirement constraint

According to the ACI Code requirements and for shear, the design of beams must satisfy the relation:

$$
V_{u} \leq \varnothing V_{n}
$$

in which $V_{n}$ is the nominal shear strength of the cross section, equals to the sum of the contributions of the concrete and the shear reinforcement if present and can be calculated from:

$$
V_{u} \leq \varnothing 6 \sqrt{f_{c}^{\prime}} b_{w} d_{b}
$$

Then Equation (36) can be written in the normalized form as:

$$
1.0-\frac{5.1 \sqrt{f_{c}^{\prime}} b_{w} d_{b}}{V_{u}} \leq 0
$$

\section{6) Crack width constraint}

According to the ACI Code, the maximum crack width of beam can be controlled by cross section dimension; number of bars placing in it and the exposure condition, accordingly the following constraint can be imposed:

$$
\frac{0.0006}{145} f_{y}\left[\frac{2\left(d^{\prime}\right)^{2} b_{w}}{n_{\min }}\right]^{1 / 3}-1.0 \leq 0
$$

where:

$d^{\prime}=$ concrete cover (to center of reinforcing steel bars).

$n_{\min }$ is the minimum number of bars in the single layer of reinforcement at top or bottom of beam.

7) Minimum beam width constraint

To ensure proper placement of concrete, the ACI Code minimize the clear distance between adjacent bars to be not less than the nominal diameter of the bars, or 1 inch. This is controlled by the width $\left(b_{r}\right)$ that required accommodating the steel area within the standard spacing and is derived according to the relation between steel area and beam width. This leads to a constraint as:

$$
\frac{6.0+2\left(n_{\max }-1\right)\left[\frac{4.2 A_{s}}{\pi n_{\max }}\right]^{1 / 2}}{b_{w}}-1.0 \leq 0
$$

\subsection{Compatibility Constraint}

An important compatibility constraint is imposed to ensure that the width of the columns at a given story is not less than the corresponding beam width to allow continuation of beam reinforcing steel bars through the columns. In the normalized form, this constraint can be written as:

$$
1.0-\frac{b_{c}}{b_{w}} \leq 0
$$

\subsection{Size Limitation Constraints}

These are upper and lower bounds imposed on beam and column dimension, and reinforcing steel areas, based on architectural and/or geometrical criteria. Such constraints have many different names in the literature, such as the side constraints, technological constraints, and simple bounds. All these names explain clearly the nature of this type of constraints mathematically.

Worth mentioning that, all the above constraints were used as constrained for the model to reach to the optimum dimensions for the beams and columns and calculated the area of steel the cost include the cost of materials and formwork, these all in turn were applied intoNeuroShell-2 software program. 


\section{Analysis and Design of the Model}

A three-bay, two-story reinforced concrete frame was selected as a model. The cross-sectional dimensions and reinforcement areas for columns and beams are taken as design variables. Namely, for columns there are three design variables: the width, the effective depth, and the longitudinal reinforcing steel area, and for beams there are three design variables: the width, the effective depth and the tensile reinforcing steel area. The preceding variables were kept constant for all beams and all columns in the two stories. The ultimate strength of concrete was taken as variable between 25 and $30 \mathrm{MPa}$ for all cases while the yield strength of steel was taken as 420 MPa for all cases. The shape of cross sections of beams and columns were kept constant as rectangular and the dimensions of $x$-sections for beams and columns are shown in Table 1 . The height of columns and spacing between columns in two directions are shown in Figure 1. The model is analyzed and designed using PROKON software by using a lot of different variables for beams and columns and after that the cost is calculated. The design is done according to the requirements of ACI Code.

\section{Optimization Design Using Artificial Neural Network (ANN)}

The results of 50 different cases of the model have been obtained with using different $\mathrm{x}$-sectional dimensions for beams and columns and using two grade of concrete (25 MPa and $30 \mathrm{MPa}$ ). The area of reinforcement obtained according to the design that verified all constraints mentioned before. The costs has been calculated using spreadsheets depending on the volume of concrete, volume of steel bars and formwork for each result obtained and named as actual costs. A neural network model is done using NeuroShell-2 program. The model is based on design results and cost calculated for each case. These results were used to train the program. The execution data of the program is the costs, it named as ANN Cost.

A comparison between the actual costs and the ANN cost is done. This comparison revealed a very small difference percentage between the two costs as clearly shown in Table 2 and Table 3 for the six selected cases for beams and columns.

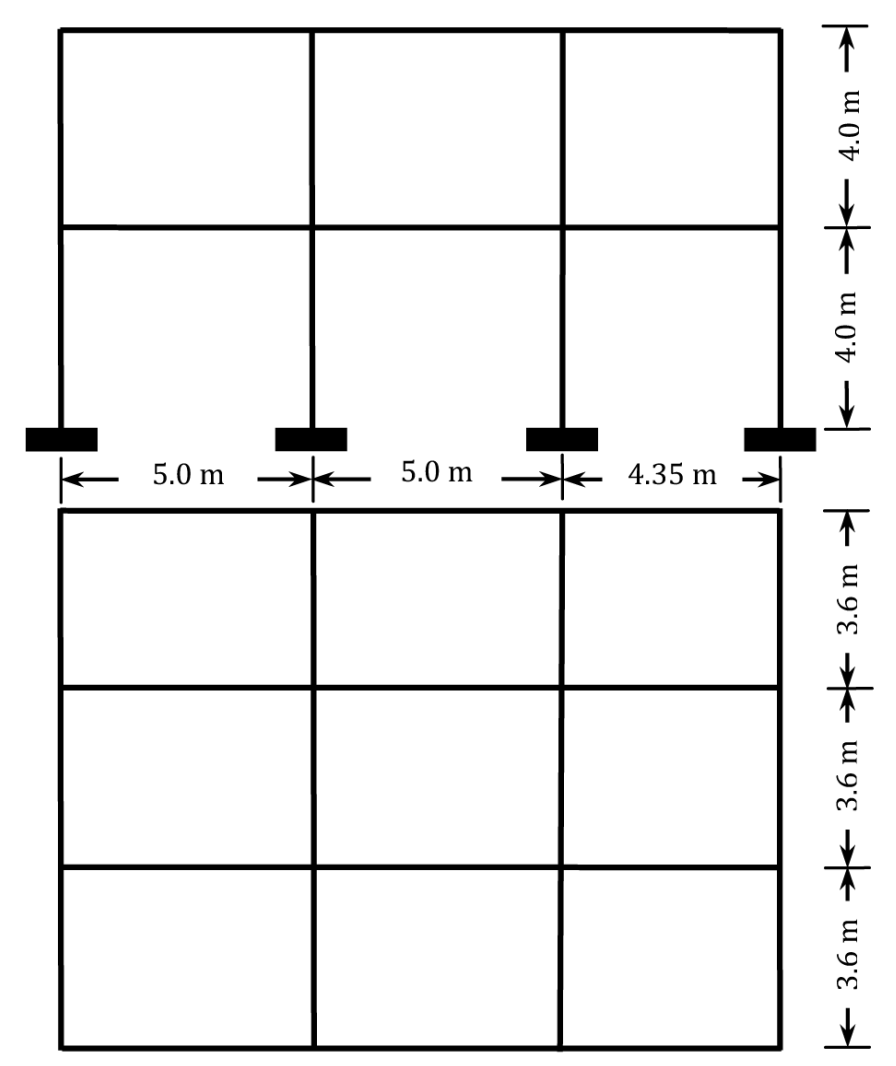

Figure 1. Model dimensions. 
Table 1. Dimensions of x-sections for beams and columns.

\begin{tabular}{ccccccccccc}
\hline x-section & \multicolumn{3}{c}{ Beam } & \multicolumn{9}{c}{ Column } \\
\hline $\mathrm{b}$ & 0.3 & 0.25 & 0.22 & 0.45 & 0.4 & 0.35 & 0.3 & 0.3 & 0.22 \\
$\mathrm{~h}$ & 0.5 & 0.5 & 0.45 & 0.45 & 0.4 & 0.35 & 0.5 & 0.3 & 0.45 \\
\hline
\end{tabular}

Table 2. Comparison between calculated costs and costs obtained using ANN model for beams.

\begin{tabular}{cccc}
\hline Case No. & Actual cost & ANN cost & Dif\% \\
\hline 1 & 529.30896 & 528.4696 & $0.16 \%$ \\
2 & 449.3835144 & 450.81342 & $-0.32 \%$ \\
3 & 587.6589966 & 587.10651 & $0.09 \%$ \\
4 & 528.6010132 & 527.8316 & $0.15 \%$ \\
6 & 449.2402649 & 448.03607 & $0.27 \%$ \\
\hline
\end{tabular}

Table 3. Comparison between calculated costs and costs obtained using ANN model for columns.

\begin{tabular}{cccc}
\hline Case No. & Actual cost & ANN cost & Dif\% \\
\hline 1 & 958.31488 & 958.332825 & $0.00 \%$ \\
2 & 1102.007 & 1101.92615 & $0.01 \%$ \\
3 & 1258.7574 & 1256.5957 & $0.17 \%$ \\
4 & 883.89771 & 884.917847 & $-0.12 \%$ \\
5 & 1101.0347 & 1100.8717 & $0.01 \%$ \\
\hline
\end{tabular}

\section{Conclusions}

In this paper, a two-story plane frame composed of beams and columns has been analyzed and designed using the PROKON program. The design is done according to the requirements of the ACI-318-08 Code, the variables used to gain optimal design are the width, depth and the area of reinforcement.

The NeuroShell-2 program based on ANN model has been applied in order to minimize the cost. More than 50 results are obtained by selecting different variables of beams and columns. These results were used for training the NeuroShell-2 program and obtaining the optimum cost.

The results obtained using NeuroShell-2 program were verified by comparing it with results obtained by calculation using spreadsheets that the comparison concluded that the two results were in a good agreement.

As conclusion, we can say that the model constructed using NeuroShell-2 program is capable of optimizing the design and can be efficient with other models of multistory buildings. Also the study can be extended using the extensive data of design obtained using various beams and columns cross-sections, different strength of concrete and different span lengths to draw relations between these variables and the area of reinforced considered, these relations if explained graphically which may help in doing quick design perfectly.

\section{References}

[1] Michell, A.G.M. (1904) The Limits of Economy of Material in Frame Structures. Philosophical Magazine, Series 6, 8, 589-597. http://dx.doi.org/10.1080/14786440409463229

[2] Schmidt, L.C. (1962) Minimum Weight Layouts of Elastic Statically Determinate Triangulated Frames under Alternative Loads System. Journal of Mechanics and Physics of Solids, 10, 139-149.

[3] Heyman, J. (1959) On the absolute Minimum Weight Design of Framed Structures. Quarterly Journal of Mechanics 
and Applied Mathematics, 12, 314-324.

[4] Krishnamoorthy, C.S. and Munro, J. (1973) Linear Program for Optimal Design of Reinforced Concrete Frames. Proceedings of IABSE, 3, 119-141.

[5] Gharehbaghia, S. and Fadaee, M.J. (2012) Design Optimization of RC Frames under Earthquake Loads. International Journal of Optimization in Civil Engineering, 2, 459-477.

[6] Moharrami, H. and Grierson, D.E. (1993) Computer Automated Design of Reinforced Concrete Frameworks. Journal of Structural Engineering (ASCE), 119, 2036-2058. http://dx.doi.org/10.1061/(ASCE)0733-9445(1993)119:7(2036)

[7] Lee, C. and Ahn, J. (2003) Flexural Design of Reinforced Concrete Frames by Genetic Algorithm. Journal of Structural Engineering (ASCE), 129, 762-774. http://dx.doi.org/10.1061/(ASCE)0733-9445(2003)129:6(762)

[8] Camp, C.V., Pezeshk, S. and Hansson, H. (2003) Flexural Design of Reinforced Concrete Frames Using a Genetic Algorithm. Journal of Structural Engineering (ASCE), 129, 105-115. http://dx.doi.org/10.1061/(ASCE)0733-9445(2003)129:1(105)

[9] Guerra, A. and Kiousis, P.D. (2006) Design Optimization of Reinforced Concrete Structures. Computers and Concrete, 3, 313-334. http://dx.doi.org/10.12989/cac.2006.3.5.313

[10] Babiker, S.A., Adam, F.M. and Mohamed, A.E. (2012) Design Optimization of Structure Concrete Beams Using Artificial Neural Network. International Journal of Engineering Inventions, 1, 07-13.

[11] http://en.wikipedia.org/wiki/Artificial_neural_network

[12] Yousif, S.T., ALsaffar, I.S. and Ahmed, S.M. (2010) Optimum Design of Singly and Doubly Reinforced Concrete Rectangular Beam Sections: Artificial Neural Networks Application. Iraqi Journal of Civil Engineering, 6, 1-19.

[13] Agha, A.B. (2013) Optimization Design of Reinforced Concrete Frames. M.Sc. Thesis, Nile Valley University, Atbara. 